\title{
The Concept of Ischemic Penumbra in Acute Stroke and Therapeutic Opportunities
}

\author{
Maurizio Paciaroni Valeria Caso Giancarlo Agnelli \\ Stroke Unit and Division of Cardiovascular Medicine, University of Perugia, Italy
}

\section{Key Words}

Penumbra Acute ischemic stroke $\cdot$ Ischemic penumbra .

Acute stroke $\cdot$ Acute stroke therapy

\begin{abstract}
Ischemic penumbra was first defined by Astrup in 1981 as perfused brain tissue at a level within the thresholds of functional impairment and morphological integrity, which has the capacity to recover if perfusion is improved. It exists, even for a short period of time in the center of ischemia, from which irreversible necrosis propagates to the neighboring tissues over time. Penumbra has become the focus of intense imaging research to differentiate it from infarction. Accurate detection of this 'tissue at risk' could be used to identify patients who would benefit most from acute treatment. Currently, recombinant tissue plasminogen activator (rtPA) is the only approved drug that has shown significant benefits in acute stroke patients when administered intravenously less than $4.5 \mathrm{~h}$ after stroke. However, its use is limited. Discrimination between infarct core and the surrounding potentially salvageable tissue is useful to better identify patients suitable for treatment. This can be achieved by positronemission tomography, single-photon-emission computed tomography, computed tomography perfusion scan and perfusion-weighted and diffusion-weighted magnetic resonance imaging. Identification of the penumbra might enable selective rtPA use in patients with large penumbras and small infarct cores, even beyond the 4.5-hour time window, where the penumbra may persist for more than $12 \mathrm{~h}$. The purpose of this review was to describe neuroimaging mo-
\end{abstract}

dalities capable of identifying penumbra tissue so as to provide surrogate markers for new trials in acute ischemic stroke patients.

Copyright $\odot 2009$ S. Karger AG, Basel

\section{Introduction}

There are a variety of definitions for ischemic penumbra [1-4]. However, the concept of 'penumbra' during focal cerebral ischemia was introduced by Astrup in 1981 [5] and refers to the regions of brain tissue, usually peripheral in location, where blood flow is sufficiently reduced to cause hypoxia, severe enough to arrest physiological function, but not so complete as to cause irreversible failure of energy metabolism and cellular necrosis [6]. As tissue tolerance to ischemic damage is dependent on residual flow and duration of flow disturbance [7], ischemic penumbra is a dynamic process. It exists for a short period of time even in the center of ischemia, where irreversible necrosis propagates to the neighboring tissue over time. This renders the time window of therapeutic opportunity variable and ill-defined; it is very short for

Search strategy and selection criteria: references for this review were identified by searches of PubMed from 1975 until October 2008 with the terms 'ischemic penumbra', 'acute stroke', 'acute stroke therapy', 'PWI/DWI RMI', 'positron emission tomography', 'single photon emission computed tomography', 'magnetic resonance imaging', 'perfusion computed tomography'.

\section{KARGER}

Fax +41613061234 E-Mail karger@karger.ch www.karger.com
(C) 2009 S. Karger AG, Base

0014-3022/09/0616-0321\$26.00/0

Accessible online at:

www.karger.com/ene
Maurizio Paciaroni

Stroke Unit and Division of Cardiovascular Medicine, University of Perugia

Santa Maria della Misericordia Hospital, Sant'Andrea delle Fratte

IT-06126 Perugia (Italy)

Tel./Fax +39075 578 2765, E-Mail mpaciaroni@med.unipg.it 
the core of ischemia and may extend to several hours in the moderately ischemic surrounding tissue [8].

Reperfusion of this ischemic brain region is the most effective therapy for acute ischemic stroke [9]. Currently, recombinant tissue plasminogen activator ( $\mathrm{rtPA}$ ) is the only approved drug for acute stroke and shows significant benefits when administered intravenously less than $4.5 \mathrm{~h}$ after stroke $[10,11]$. However, its use is limited because a large proportion of patients are admitted more than $4.5 \mathrm{~h}$ after symptom onset [12]. In addition to a number of contraindications, uncertainties regarding selection criteria for patients who might benefit from thrombolysis contribute to the low rate of stroke patients treated with rtPA. Discrimination between infarct core and surrounding, potentially salvageable, tissue is useful for better identification of patients suitable for treatment. This can be achieved by positron emission tomography (PET), single-photon-emission computed tomography (SPECT), computed tomography (CT) perfusion scan and perfusion-weighted (PW) and diffusion-weighted (DW) magnetic resonance imaging (MRI). Identification of the penumbra might allow for selective rtPA use in those patients with a large penumbra and a small infarct core even beyond the 4.5 -hour time window, where it has been shown that the penumbra may persist for more than $12 \mathrm{~h}$.

\section{Experimental Basis of the Ischemic Penumbra}

The idea that there exist two ischemic thresholds in the pathogenesis of cerebral infarction, one for functional impairment and the other for morphological damage, the perfused penumbra tissue ranging between these two values, came from seminal microelectrode studies on the baboon cortex in the late 1970s, which measured the effects of progressive reductions in cerebral blood flow (CBF) $[13,14]$. These studies described a level of CBF reduction that led to cessation of cortical evoked responses in the absence of terminal increases in extracellular potassium or reductions in $\mathrm{pH}$ and an even greater decrease in $\mathrm{CBF}$, where large increases in extracellular potassium and reductions in $\mathrm{pH}$ indicative of failure of membrane ion homeostasis and cell death occurred [15]. The interaction between severity and duration of ischemia in the development of irreversible cell damage was also studied by simultaneous recordings of cortical neuronal activity and local blood flow in cats [7]. Blood flow rates of approximately 0,10 , and $15 \mathrm{ml} \cdot 100 \mathrm{~g}^{-1} \cdot \mathrm{min}^{-1}$ maintained for periods of 25,40 , and $80 \mathrm{~min}$, respectively, are the worst possible constellation of residual blood flow and duration of ischemia that still permits neuronal recovery [8]. Differences among species must be taken into consideration when experimental results are compared. In monkeys and cats, large infarcts develop with residual flow rates of $12 \mathrm{ml} \cdot 100 \mathrm{~g}^{-1} \cdot \mathrm{min}^{-1}$ lasting for up to $2-3 \mathrm{~h}$ $[16,17]$, and individual cells may become necrotic at lower flow values after shorter periods of time [1]. However, middle cerebral artery (MCA) occlusion in rats induces selective neuronal necrosis in the caudate-putamen after only $15 \mathrm{~min}$, localized infarcts in the caudate-putamen and selective neuronal necrosis in the neocortex after 30 $\mathrm{min}$, and cortical infarcts after $60 \mathrm{~min}$. With an occlusion time of 120-180 min, infarct sizes increase and reach those found after permanent MCA occlusion $[8,19]$.

Though the ischemic penumbra has been described on the basis of blood flow and physiological parameters, ischemic cell damage involves a cascade of biochemical and molecular mechanisms. The influx of $\mathrm{Ca}^{2+}$ into cells, the release of excitatory amino acids, and the activation of receptors and receptor-operated ion channels are key mechanisms in the biochemical cascade leading to tissue damage [20]. Protein synthesis reduction/arrest is the earliest and most sensitive metabolic response to ischemia that may be reversible in the penumbra but not in the core [21]. This occurs after CBF reductions of only $50 \%$ and is not caused by failure of energy metabolism because adenosine triphosphate (ATP) depletion is not observed until CBF decreases to 20\% [22]. In addition, apoptosis-related genes induced after focal ischemia may contribute to cell death in the core and selective cell death adjacent to an infarct [23]. More recently, DNA microarray studies have identified large numbers of genes that are either upregulated or downregulated after temporary MCA occlusion in rats [24-27]. Gene-regulated responses to focal cerebral ischemia, thought to affect outcome and have therapeutic implications, have been investigated and include adhesion molecules, cytokines, chemokines, matrix metalloproteinases, apoptosis-inducing genes, DNA repair genes, nitric oxide synthase, tumor necrosis factor, NF- $\mathrm{kB}$, interleukins, COX-2 and growth factors $[23,28]$.

Concerning neuronal recovery in the penumbra around a focal infarction, recent findings have revealed that synapses and their networks express a high degree of functional and structural plasticity [29]. Synapses, synaptic vesicles, axon terminals, and spines were reported to degenerate with a reduction in their numbers and sizes, until after 4 days and then recover from 1 to 12 weeks after the ischemic insult [30]. 
These results document the complexity of the molecular events that characterize brain tissue response to incomplete focal ischemia [31].

\section{Methods for Imaging the Penumbra in Humans}

CT selects stroke patients for thrombolysis on the basis of the absence of hemorrhage and the presence of early CT ischemic changes. Since patients with an ischemic penumbra are more likely than those without to respond to therapy, identification of the former is fundamental [32]. From the mid 1970s, PET, SPECT, and MRI have enabled investigators to assess brain function. Recently, the development of ultrafast CT equipment has led to increased availability of CT perfusion that evaluates $\mathrm{CBF}$ and cerebral blood volume (CBV) qualitatively [33]. Furthermore, these neuroimaging techniques permit to distinguish stroke patients from those with stroke-mimicking conditions.

\section{Positron Emission Tomography}

Early pathophysiological changes occurring after focal ischemia can be followed by PET, which provides quantitative maps of several important physiological variables, including regional $\mathrm{CBF}$, regional $\mathrm{CBV}(\mathrm{rCBV})$, regional cerebral metabolic rate of oxygen $\left(\mathrm{rCMRO}_{2}\right)$, and regional cerebral metabolic rate of glucose as well as neurotransmitters and neuroreceptors such as benzodiazepine receptors (BZRs) with flumazenil, an accurate marker of neuronal loss [8, 34]. As PET is considered the gold standard for these measurements, it is also used to evaluate the degree of ischemic brain damage. Multitracer studies have defined the penumbra as reduced $\mathrm{CBF}$ tissue with preserved $\mathrm{CMRO}_{2}$ and increased oxygen extraction fraction (OEF) $[2,8]$. Regarding irreversible tissue damage at the time of investigation (usually several hours after the ischemic event), $\mathrm{CMRO}_{2}$ is the most reliable parameter with about $65 \mu \mathrm{mol} \cdot 100 \mathrm{~g}^{-1} \cdot \mathrm{min}^{-1}$ as its threshold. Studies examining early $\mathrm{CBF}$ and $\mathrm{CMRO}_{2}$ measurements in infarcts identified on late $\mathrm{CT}$ scans and a flow threshold of $12 \mathrm{ml} \cdot 100 \mathrm{~g}^{-1} \cdot \mathrm{min}^{-1}$ were described, which also predicted irreversible damage [35]. Relatively preserved $\mathrm{CMRO}_{2}$ was accepted as an indicator of maintained neuronal function in regions with severely reduced CBF. Regions with CBF between 12 and $22 \mathrm{ml} \cdot 100$ $\mathrm{g}^{-1} \cdot \mathrm{min}^{-1}$ display an unstable metabolic situation. In these areas, infarction will develop if low flow values per- sist, and thus are considered to be in the penumbra zone [36]. However, this method is complex, invasive (it needs arterial blood sampling) and costly, and requires multitracer application. Central BZR ligands are thought to be markers of neuronal integrity [37]. Labeled BZR ligands have been successfully used to distinguish between infarcted and deactivated tissues after stroke $[38,39]$. Labeled flumazenil was administered 3-16 h from symptom onset to 10 patients with acute ischemic stroke [40]. The early changes in flow, oxygen consumption, and flumazenil binding were compared with permanent disturbances of glucose metabolism while the final infarct sizes were determined using MRI or CT, 12-22 days after stroke. Cortical regions with reduced flumazenil binding, usually within the larger areas of disturbed blood flow, predicted the final infarcts while, in 1 case, areas with severely depressed glucose metabolism were indicative of marked neuronal loss. The predictive value of reduced flumazenil binding was comparable to that of $\mathrm{rCMRO}_{2}$ reduction $\left(<60 \mu \mathrm{mol} \cdot 100 \mathrm{~g}^{-1} \cdot \mathrm{min}^{-1}\right)$. In these areas, OEF could still be increased, limiting the usefulness of this variable as an indicator of viability. Unlike studies with oxygen tracers, the use of BZR ligand does not require arterial puncture and patient cooperation; in addition, it produces superior image quality and has the potential of SPECT application [8]. Moreover, perfusion can be assessed by following the early distribution of the same tracer. This makes BZR radioligands useful in acute ischemic stroke.

In a study in which the final infarcts were analyzed with respect to flow values and flumazenil uptake in the first hours after stroke, probability thresholds of flumazenil binding and blood flow could be calculated in order to predict the final state of the tissue and define the range of the penumbra [41]. As the $95 \%$ prediction limit for infarction, a flumazenil uptake of 3.4 times the average uptake in the white matter was found; as the flow range in the penumbra, $4.8-14.1 \mu \mathrm{mol} \cdot 100 \mathrm{~g}^{-1} \cdot \mathrm{min}^{-1}$ were obtained.

The fact that BZR radioligands can actually be used to select patients was shown in another study of 11 patients with hemispheric stroke in whom thrombolysis had been started within $3 \mathrm{~h}$ of symptom onset [42]. At the beginning of thrombolysis, cortical CBF and flumazenil binding were assessed by PET. Those early PET findings were related to a change in neurological deficit and to the extent of cortical damage on MRI or CT 3 weeks after stroke. Hypoperfusion was observed in all cases, and in 8 patients the values were below the critical thresholds estimated at $12 \mathrm{ml} \cdot 100 \mathrm{~g}^{-1} \cdot \mathrm{min}^{-1}$, comprising 1-174 ml of cortical tissue. Substantial reperfusion was seen in 
most of these regions $24 \mathrm{~h}$ after thrombolysis. In 4 cases, distinct areas of decreased flumazenil binding were detected. These patients suffered from permanent lesions in cortical areas corresponding to their flumazenil defects (112 vs. 146,3 vs. 3,2 vs. 1 , and 128 vs. $136 \mathrm{ml}$ ). In the other patients, no morphological defects were detected on MRI or CT, although blood flow was critically decreased in areas with volumes of up to $78 \mathrm{ml}$ before thrombolysis. These findings suggest that in BZR imaging with flumazenil, PET distinguishes between irreversibly damaged and viable penumbra tissue early after stroke and can be used to identify patients who can benefit from reperfusion therapy.

Due to the low concentrations of BZRs in the white matter and basal ganglia, these values apply only to the cortex but still permit a reliable measure of irreversibly damaged and potentially salvageable portions of an ischemic area

As a tracer of hypoxic viable tissue, ${ }^{18} \mathrm{~F}$-fluoromisonidazole (FMISO) could also be used to detect an ischemic penumbra $[35,43]$. Areas exhibiting increased FMISO uptake have been detected 6.25-42.5 h after stroke and reported to be maximal in the first hours after symptom onset. They declined with time and disappeared after several days. The areas were usually distributed over the periphery of the infarct identified on late CT, but extended into normal tissue adjacent to the infarct in a few cases [44]. These findings suggest that FMISO binding is increased in tissue at risk and mirrors the temporal and spatial distribution of penumbras. However, these results need direct calibration by conventional PET measurements. Since reliable detection of FMISO uptake is delayed ( $>2 \mathrm{~h}$ between tracer injection and imaging), the value of this tracer is limited for therapeutic decisions in the acute phase of ischemic stroke [35].

PET is the oldest imaging technique employed for penumbra detection and is currently considered the gold standard. However, the use of PET is limited due to its cost, the complex logistics involving a multidisciplinary team, and patient access is quite limited during the acute phase of stroke [33]. Therefore, multisequence procedures have greatly evolved over time, making these modalities a reliable tool in the study of acute ischemic stroke.

\section{Single-Photon-Emission Computed Tomography}

In the stroke setting, SPECT has been used for the evaluation of cerebral perfusion $[45,46]$. However, only when ${ }^{133} \mathrm{Xe}$ is used and the clearance of this inert gas is followed can $\mathrm{rCBF}$ be quantified [47]. Handling of the radioactive gas, the complexity of data analysis, and the rather coarse spatial resolution obtained with this tracer limit the routine application of this technique [8]. The tracer most often used in acute ischemic stroke is ${ }^{99 \mathrm{~m} T c-}$ hexamethylpropylene-amino-oxime, which replaced ${ }^{123} \mathrm{I}-\mathrm{N}$-isopropyl- $p$-iodoamphetamine for perfusion studies. The newer tracer ${ }^{99 \mathrm{~m}} \mathrm{Tc}$-ethyl-cysteinate-dimer (ECD) reflects both perfusion and the metabolic status of the tissues as the retention of ECD requires the presence of cytosolic esterase and therefore depends on the presence of viable cells [8]. In addition to the radiotracers designed to measure perfusion, there are also a number of agents used to measure various aspects of neurochemistry. These radiotracers enable the quantification of presynaptic and postsynaptic neuroreceptors and neurotransmitter synthesis. Such neurochemical studies show promise for assessing diseases in which abnormalities of a single neurotransmitter play a prominent pathophysiological role.

In acute ischemic stroke, detection of a penumbra based on SPECT studies alone is difficult because the obtained values are relative perfusion measures standardized against contralateral or cerebellar regions and the functional and morphologic states of the tissue are assessed only indirectly. Earlier SPECT studies failed to show any advantage of SPECT over a structured clinical evaluation in predicting the evolution of acute stroke [48]. However, using ECD in the first $6 \mathrm{~h}$ after stroke, Barthel et al. [49] were able to predict which patients would develop massive necrosis of the MCA territory. Other studies have suggested that patients with a normal SPECT scan, performed within 3-6 h from stroke onset, will most likely recover spontaneously and therefore may not benefit from thrombolysis [50-52]. Furthermore, studies performed at a later time after the onset of symptoms could also identify different tissue compartments and SPECT results could help predict neurological development in addition to neurological scores $[53,54]$.

It can be concluded that severely reduced tracer uptake over a large area is associated with poor outcome whereas normal or increased uptake is predictive of a good clinical outcome. The level of flow decrease that predicts extended infarction or hemorrhagic complications was estimated at different values and varied between complete lack of ECD uptake and a relative decrease in perfusion to $35-60 \%$ of the contralateral value [55-57]. The threshold for a moderately ischemic area with a good chance of recovery was set at $70 \%$ of contralateral tracer uptake in several studies $[58,59]$.

SPECT is beneficial in the evaluation of acute stroke but, unfortunately, the need to perform either CT or MRI 
in the acute phase makes it difficult to perform SPECT within the time frame allotted for the evaluation of these patients [46].

\section{Magnetic Resonance Imaging}

Today, several centers use MRI, including PW/DW imaging (PWI/DWI), as a diagnostic tool for hyperacute stroke before deciding on therapy. Hyperintense areas on DWI are generally believed to represent irreversible ischemic changes [60], and the apparent diffusion coefficient of water (ADC) can be calculated from DWI as a comparative measure. PWI requires the intravenous administration of gadolinium and provides information about brain tissue perfusion at a given time.

DWI shows the area of reduced diffusion as a hyperintense region, which follows the redistribution of water from the extracellular to intracellular space as a consequence of reduced ATPase activity [61]. In the core of this area, ATP remains depleted, indicating necrotic transformation because of severely reduced perfusion [62]. As disturbances of the water-ionic homeostasis occur immediately with the disruption of perfusion, DWI is able to detect the initial ischemic disturbance within $2.5 \mathrm{~min}$ after arterial occlusion $[63,64]$. ADC values gradually normalize in 5-10 days and then increase in chronic lesions [65]. This gradual increase may indicate the development of vasogenic edema and cellular necrosis [66]. However, the DWI lesion persists for another week or so because DWI also detects prolonged $\mathrm{T}_{2}$ signals. The changes in DWI signals correlate with histological defects and metabolic abnormalities as assessed by autoradiographic and chemical imaging procedures at follow-up [67]. Diffusion lesions may be heterogeneous in the early stages of ischemia in humans. Within $6 \mathrm{~h}$ of stroke onset, DWI has a reported sensitivity of $95 \%$ and a specificity of nearly $100 \%$ [68]. Multiple experimental and human studies have demonstrated that in the first few hours after ischemia onset, some DWI changes are reversible, generally those associated with less severe ADC changes [69-71].

PWI by bolus tracking demonstrates regions of hemodynamic abnormality [72]. The most widely used indicator of brain perfusion is the 'time-to-peak', i.e. the time until the greatest concentration of gadolinium is achieved in each voxel. PWI can be converted into maps of relative $\mathrm{CBV}$, qualitative mean transit time (MTT), and relative CBF [73]. The regions defined as the ischemic penumbra were characterized by a mean $73 \%$ increase in MTT of the gadolinium bolus and a 29\% increase in relative CBV.
This model-independent measure allows an estimation of the severity of ischemia in comparison with the nonaffected hemisphere [74]. The most widespread technique used in current studies is deconvolution of the arterial input function, which yields quasi-absolute measures and does not involve comparison with the uninvolved site. The PWI parameter used is $\mathrm{T}_{\max }$, which is the deconvoluted time to peak $[75,76] . \mathrm{T}_{\max }$ is the maximum of the tissue residue function characteristics to each voxel and reflects how much the tissue response lags behind the stimulus by an arterial input into the voxel and inherently corrects for the length of the gadolinium bolus. $T_{\max }$ has been shown to be a sensitive parameter to detect perfusion deficits and tissues condemned to infarction [77].

The PWI/DWI mismatch region, defined as the difference in volume of tissue between the smaller diffusion lesion and the larger perfusion deficit, is thought to approximately correspond to the ischemic penumbra [78]. However, there are several observations to make.

First, several authors have demonstrated that diffusion lesions may be partially or even fully reversible when reperfusion occurs within $2-3 \mathrm{~h}[61,64,79-81]$ and in as many as $20 \%$ of patients in the 6-hour time window [69$71,80]$. DWI changes seem to reflect much more complex pathophysiological changes than was originally thought, and more experimental and observational data are needed to clarify this issue. However, for practical purposes, the majority of the DWI seems to reflect the infarct core and can be used as a useful index for its extent within the first hours of ischemic stroke [32].

The second observation applies to the results of Schlaug et al. [78], who analyzed the extension of the diffusion lesion into the impaired reperfusion area on the first day after stroke and 24-72 h later. Decreases in $\mathrm{rCBF}$ to $37 \%$ and decreases of rCBV to $47 \%$ in the contralateral region were used to identify penumbral tissue, whereas the ischemic core showed a more severe reduction in $\operatorname{rCBF}(12 \%$ of the contralateral region) and $\mathrm{rCBV}$ (19\% of the contralateral region). The operationally defined values for penumbra and core (37 and $12 \%$ of the contralateral region, respectively) may be translated into CBF values (18.5 and $6 \mathrm{ml} \cdot 100 \mathrm{~g}^{-1} \cdot \mathrm{min}^{-1}$, respectively) and correspond to the values obtained in quantitative PET studies. The diffusion abnormality enlarged to $376.6 \%$ into the region of hypoperfusion within $48 \mathrm{~h}$ in all the patients, but did not reach the full volume of the initial perfusion abnormality (59.2 vs. $96.6 \mathrm{ml}$, on average). An explanation for this anomaly could be that with semiquantitative perfusion measures such as seen with PWI, the distinction between benign oligoemia and true pen- 
umbral tissue is unclear. As blood flow within the brain falls, there is a substantial oligoemic reserve where brain tissue remains functionally unaffected [8]. PWI does definitely show benign oligoemia. Hence, the mismatch between PWI and DWI could be much larger than the true penumbra [32]. The probability of infarction increases with the severity of the transit time delay. $T_{\max }$ of $4-6 \mathrm{~s}$ has been most closely correlated with the final infarct volume. This has led to the conclusion that transit time delays $<4-6 s$ are likely benign [82]. Other authors have shown that identification of absolute PWI thresholds for infarction is not possible because they are time dependent and concluded that there is no single threshold and, therefore, no mismatch definition that can predict tissue fate for all patients. For the time being, it is reasonable to use $T_{\max }$, recognizing that this is only an estimate of the tissue at risk $[83,84]$. A recent study that directly compared MRI perfusion with PET data in acute stroke indicated that a $\mathrm{T}_{\max }$ of more than $5.5 \mathrm{~s}$ best indicated the penumbra [85].

Despite these imaging uncertainties, MRI mismatch is reasonably robust in representing the at-risk tissue and it remains the most practical tool for identifying at-risk cerebral tissue during the early phase of acute stroke [32]. Kidwell et al. [86] performed an analysis on a subset of patients treated with mechanical embolectomy up to $8 \mathrm{~h}$ from symptom onset and subjected them to MRI before and after embolectomy. Approximately half of the patients had a penumbra pattern before treatment and recanalization was achieved in $70 \%$ of them. At day 90 , $89 \%$ of patients with a penumbral pattern and recanalization had a good outcome compared with only $14 \%$ of patients without a penumbral pattern but with recanalization. These data suggest that only patients with an MRI-defined penumbra pattern are likely to benefit from therapy [86]. Clinical trials [75, 88-90] support that it is safe and effective to expand the time window for rtPA to up to $6 \mathrm{~h}$ in patients with tissue at risk as defined by MRI. In fact, in stroke patients treated 3-6 h after symptom onset, early reperfusion was associated with significantly increased odds of achieving a favorable clinical response in patients with a perfusion/diffusion mismatch and a lower rate of symptomatic intracerebral hemorrhage. Patients without mismatch did not appear to benefit from early reperfusion [91, 92]. Recently, EPITHET, a placebo-controlled randomized study [76], found that alteplase was nonsignificantly associated with lower infarct growth and significantly associated with increased reperfusion in patients who had a mismatch on MRI. However, a phase III trial (DIAS-II), that had a pri- mary clinical outcome, was negative [93]. Despite these uncertainties, other trials are using the penumbra paradigm [94].

\section{Perfusion Computed Tomography}

Brain CT scan is the examination most frequently used for the emergent evaluation of patients with acute stroke because of its wide availability and proven benefit. It has been utilized as a screening tool in most of the major therapeutic trials conducted to date [10]. Conventional CT scans are useful for distinguishing between ischemic stroke and intracerebral or subarachnoid hemorrhage, and can also rule out other conditions that could mimic stroke such as brain tumors. More recently, CT has been used to detect very early ischemic changes within the first few hours of ischemic stroke [46, 95]. Scanning time has been shortened with the advent of helical CT scanners. This enables tracking of an intravenously infused contrast bolus in the vascular bed and the identification of major-artery occlusions by CT angiography [96]. By continuous scanning of the entire brain after CT angiography, tissue perfusion can be assessed and regions distal to a vascular occlusion can be identified because they appear hypodense or hypoperfused relative to the rest of the brain [8]. Perfusion CT techniques, such as slow-infusion/whole brain perfusion CT and dynamic perfusion CT, may help distinguish irreversible infarction from other tissues. Slow-infusion perfusion CT is useful for evaluating the perfusion of the entire brain, but provides only qualitative information related to CBV and therefore cannot be used to differentiate reversible from nonreversible ischemia $[96,97]$. Dynamic perfusion CT involves dynamic acquisition of sequential CT slices during the intravenous administration of iodinated contrast media [98] and enables estimation of CBF, CBV and MTT. Areas with prolonged MTT are hemodynamically compromised. In these areas, the regions with increased CBV resulting from vasodilatation and collateral recruitment are considered to have preserved autoregulation and to represent 'tissue at risk' whereas regions with decreased CBV correspond to the infarct core [99, 100]. Relative CBV thresholds (compared with the contralateral hemisphere) in hypoperfused tissue destined to infarct or to survive, are similar to those described for SPECT or PET and therefore might enable definition of the penumbra [101]. However, most CTs performed after processing analyses defining infarct cores do not use relative CBV for this purpose: they use quasi-absolute CBV obtained by 
deconvolution either with venous output or arterial input. In a study, 42 stroke patients successively underwent perfusion CT/CT angiography and MRI examinations within 3-9 $\mathrm{h}$ following symptom onset; 14 would have been suitable candidates for reperfusion treatment based on MRI findings. The correlation between perfusion CT/CT angiography and MRI was excellent for infarct size, cortical involvement, and internal cerebral artery occlusion and substantial for penumbra/infarct ratio. Relying on MRI or perfusion CT/CT angiography would have led to the same treatment decisions in all cases but 1 [102].

\section{Therapeutic Opportunities}

Within $3 \mathrm{~h}$ of symptom onset, all randomized controlled trials of patients treated with rtPA are examined with simple CTs and this remains the typical method of decision-making in acute MCA strokes in most centers. Screening for eligibility for intravenous thrombolysis within $3 \mathrm{~h}$ of stroke with MRI was feasible at an experienced center, but at the expense of delay of about $20 \mathrm{~min}$ in treatment [103]. Using penumbral imaging permits to exclude patients within the 4.5 -hour window who will not benefit from recanalization therapy. This is because they have either already completed their infarct or because they have already spontaneously recanalized/reperfused. While such patients are very infrequent in the 0 - to 3-hour window, they are not uncommon in the 3to 4.5 -hour window. In the 4.5- to 6-hour period after stroke onset, treatment by revascularization is supported by more limited evidence even if there is support showing the value of reperfusion in the 3 - to 6-hour window based on appropriate patient selection. For the time being, the body of evidence for MRI variables, particularly DWI/ PWI mismatch, is greater than for CT perfusion maps [103]. Because CT is not as sensitive as DWI for the detection of lacunar or posterior fossa strokes, MRI has clear advantages over CT perfusion - unless time is a constraint. Furthermore, almost all current CT perfusion techniques lack whole-brain coverage. CT perfusion can be used instead if patients are unsuitable for MRI, and may be preferred in the future if the penumbra is validated in larger series [104]. MRI and CT perfusion as well as PET and SPECT can also be valuable in patients with stroke presenting more than $6 \mathrm{~h}$ after symptom onset, in patients with unknown time of onset (e.g. 'awakening stroke') $[105,106]$, in patients with stroke in progression [107], and in patients with malignant MCA stroke, who may benefit from other treatments (e.g. decompressive craniectomy). Currently, PET and SPECT have a more limited role in the evaluation of acute stroke due to their costs and current lack of availability.

\section{Conclusions}

Discrimination between infarct core and surrounding potentially salvageable tissue is important so as to better identify patients suitable for treatment. This can be achieved by PET, SPECT, CT perfusion scan and PWI/ DWI. Identification of the penumbra could enable a better selection for rtPA use among patients with large penumbras and small infarct cores even beyond the 4.5-hour time window as it has been shown that the penumbra may persist for more than $12 \mathrm{~h}$.

\section{References}

1 Hakim AM: The cerebral ischemic penumbra. Can J Neurol Sci 1987;14:557-559.

$\checkmark 2$ Baron JC: Mapping the ischemic penumbra with PET: implications for acute stroke treatment. Cerebrovasc Dis 1999;9:193-201.

3 Hossmann KA: Viability thresholds and the penumbra of focal ischemia. Ann Neurol 1994:36:557-565.

4 Ginsberg MD, Pulsinelli WA: The ischemic penumbra, injury, thresholds, and the therapeutic window for acute stroke. Ann Neurol 1994:36:553-554.

5 Astrup J, Siesjo BK, Symon L: Thresholds in cerebral ischemia - the ischemic penumbra. Stroke 1981;12:723-725.

Ischemic Penumbra in Acute Stroke and Therapeutic Opportunities
6 Ginsberg MD: Adventures in the pathophysiology of brain ischemia: penumbra, gene expression, neuroprotection: the 2002 Thomas Willis Lecture. Stroke 2003;34:214-223.

7 Heiss WD, Rosner G: Functional recovery of cortical neurons as related to degree and duration of ischemia. Ann Neurol 1983;14:294301.

8 Heiss WD: Ischemic penombra: evidence from functional imaging in man. J Cereb Blood Flow Metab 2000;20:1276-1293.

-9 NINDS: Tissue plasminogen activator for acute ischemic stroke. The National Institute of Neurological Disorders and Stroke rt-PA Stroke Study Group. N Engl J Med 1995;333; 1581-1587.
10 Hacke W, Donnan G, Fieschi C, et al: ATLANTIS Trials Investigators; ECASS Trials Investigators; NINDS rt-PA Study. 2004. Association of outcome with early stroke treatment: pooled analysis of ATLANTIS, ECASS, and NINDS rt-PA stroke trials Group Investigators. Lancet 2004;363:768-774.

11 Hacke W, Kaste M, Bluhmki E, et al: Thrombolysis with alteplase 3 to $4.5 \mathrm{~h}$ after acute ischemic stroke. N Engl J Med 2008;359: 1317-1329.

12 Kleindorfer D, Kissela B, Schneider A, et al: Eligibility for recombinant tissue plasminogen activator in acute ischemic stroke: a population-based study. Stroke 2004;35:e27e29. 
13 Branston NM, Strong AJ, Symon L: Extracellular potassium activity, evoked potential and tissue blood flow: relationship during progressive ischemia in baboon cerebral cortex. J Neurol Sci 1977;32:305-321.

- 14 Astrup J, Symon L, Branston NM, Lassen NA: Cortical evoked potential and extracellular $\mathrm{K}^{+}$and $\mathrm{H}^{+}$at critical levels of brain ischemia. Stroke 1977;8:51-57.

15 Warach S: Measurement of the ischemic penumbra with MRI: it's about time. Stroke 2003;34:2533-2534.

16 Jones TH, Morawetz RB, Crowell RM, et al: Thresholds of focal cerebral ischemia in awake monkeys. J Neurosurg 1981;54:773782.

-17 Marcoux FW, Morawetz RB, Crowell RM, et al: Differential regional vulnerability in transient focal cerebral ischemia. Stroke 1982;13:339-346.

-18 Pulsinelli WA, Brierley JB, Plum F: Temporal profile of neuronal damage in a model of transient forebrain ischemia. Ann Neurol 1982;11:491-498.

19 Memezawa H, Smith ML, Siesjo BK: Penumbral tissues salvaged by reperfusion following middle cerebral artery occlusion in rats. Stroke 1992;23:552-559.

20 Siesjo BK: Pathophysiology and treatment of focal cerebral ischemia. II. Mechanisms of damage and treatment. J Neurosurg 1992;77: 337-354.

21 Weinstein PR, Hong S, Sharp FR: Molecular identification of the ischemic penumbra. Stroke 2004;35:2666-2670.

-22 Mies G, Ishimaru S, Xie Y, Seo K, Hossmann $\mathrm{KA}$ : Ischemic thresholds of cerebral protein synthesis and energy state following middle cerebral artery occlusion in rat. J Cereb Blood Flow Metab 1991;11:753-761.

-23 Sharp FR, Lu A, Tang Y, Millhorn DE: Multiple molecular penumbras after focal cerebral ischemia. J Cereb Blood Flow Metab 2000;20:1011-1032.

24 Schmidt-Kastner R, Zhang B, Belayev L, et al: DNA microarray analysis of cortical gene expression during early recirculation after focal brain ischemia in rat. Brain Res Mol Brain Res 2002;108:81-93.

-25 Rajdev S, Hara K, Kokubo Y, et al: Mice overexpressing rat heat shock protein 70 are protected against cerebral infarction. Ann Neurol 2000;47:782-791.

-26 Bergeron M, Yu AY, Solway KE, et al: Induction of hypoxia-inducible factor-1 (HIF-1) and its target genes following focal ischemia in rat brain. Eur J Neurosci 1999;11:41594170.

-27 Kinouchi H, Sharp FR, Chan PH, et al: Induction of c-fos, junB, c-jun and HSP70 mRNA in cortex, thalamus, basal ganglia, and hippocampus following middle cerebral artery occlusion. J Cereb Blood Flow Metab 1994;14:808-817.
28 Pabello NG, Tracy SJ, Snyder-Keller A, Keller RW Jr: Regional expression of constitutive and inducible transcription factors following transient focal ischemia in the neonatal rat: influence of hypothermia. Brain Res 2005;15:11-21.

29 Luscher C, Nicoll RA, Malenka RC, Muller D: Synaptic plasticity and dynamic modulation of the postsynaptic membrane. Nat Neurosci 2000;3:545-550.

30 Ito U, Kuroiwa T, Nagasao J, et al: Temporal profiles of axon terminals, synapses and spines in the ischemic penumbra of the cerebral cortex: ultrastructure of neuronal remodelling. Stroke 2006;37:2134-2139.

31 Lo EH: A new penumbra: transitioning from injury into repair after stroke. Nat Med 2008; 14:497-500.

32 Donnan GA, Davis SM: Neuroimaging, the ischemic penumbra, and selection of patients for acute stroke therapy. Lancet Neurology 2002;1:417-425.

33 Fisher M, Ginsberg M: Current concepts of the ischemic penumbra. Introduction. Stroke 2004;35:2657-2658.

34 Heiss WD, Sobesky J, Smekal V, et al: Probability of cortical infarction predicted by flumazenil binding and diffusion-weighted imaging signal intensity. A comparative positron emission tomography/magnetic resonance imaging study in early ischemic stroke. Stroke 2004;35:1892-1898.

35 Heiss WD: Best measure of ischemic penumbra: positron emission tomography. Stroke 2003;34:2534-2535.

36 Hakim AM, Evans AC, Berger L, et al: The effect of nimodipine on the evolution of human cerebral infarction studied by PET. J Cereb Blood Flow Metab 1989;9:523-534.

-37 Sette G, Baron JC, Young AR, et al: In vivo mapping of brain benzodiazepine receptor changes by positron emission tomography after focal ischemia in the anesthetized baboon. Stroke 1993;24:2046-2058.

38 Hatazawa J, Satoh T, Shimosegawa E, et al: Evaluation of cerebral infarction with iodine 123-iomazenil SPECT. J Nucl Med 1995;36: 2154-2161.

-39 Nakagawara J, Sperling B, Lassen NA: Incomplete brain infarction of reperfused cortex may be quantitated with iomazenil. Stroke 1997;28:124-132.

40 Heiss WD, Ground M, Thiel A, et al: Permanent cortical damage detected by flumazenil positron emission tomography in acute stroke. Stroke 1998;29:454-461.

41 Heiss WD, Kracht LW, Thiel A, et al: Penumbral probability thresholds of cortical flumazenil binding and blood flow predicting tissue outcome in patients with cerebral ischemia. Brain 2001;124:20-29.

42 Heiss WD, Kracht L, Grond M, et al: Early $\left[{ }^{11} \mathrm{C}\right]$ flumazenil/ $\mathrm{H}_{2} \mathrm{O}$ positron emission tomography predicts irreversible ischemic cortical damage in stroke patients receiving acute thrombolytic therapy. Stroke 2000;31: 366-369.
43 Saita K, Chen M, Spratt NJ, et al: Imaging the ischemic penumbra with ${ }^{18} \mathrm{~F}$-fluoromisonidazole in a rat model of ischemic stroke. Stroke 2004;35:975-980.

$\checkmark 44$ Read SJ, Hirano T, Abbott DF, et al: Identifyng hypoxic tissue after acute ischemic stroke using PET and ${ }^{18} \mathrm{~F}$-fluoromisonidazole. Neurology 1998;51:1617-1621.

45 Holman BL, Devous MD Sr: Functional brain SPECT: the emergence of a powerful clinical method. J Nucl Med 1992;33:18881904.

46 Masdeu JC, Irimia P, Asenbaum S, et al: EFNS guidelines on neuroimaging in acute stroke. Report of an EFNS task force. Eur J Neurol 2006;13:1271-1283.

47 Lassen NA: Cerebral blood flow quantification in clinical routine studies: how far have we now come? J Nucl Med 1995;36:23432344.

48 Bowler JV, Wade JP, Jones BE, et al: Singlephoton emission computed tomography using hexamethylpropyleneamine oxime in the prognosis of acute cerebral infarction. Stroke 1996;27:82-86.

49 Barthel H, Hesse S, Dannenberg C, et al: Prospective value of perfusion and $\mathrm{x}$-ray attenuation imaging with single-photon emission and transmission computed tomography in acute cerebral ischemia. Stroke 2001;32: 1588-1597.

-50 Alexandrov AV, Masdeu JC, Devous M Sr, et al: Brain single-photon emission CT with HMPAO and safety of thrombolytic therapy in acute ischemic stroke. Stroke 1997;28: 1830-1834.

51 Hirano T, Read SJ, Abbott DF, et al: Prediction of the final infarct volume within $6 \mathrm{~h}$ of stroke using single photon emission computed tomography with technetium-99m hexamethylpropylene amine oxime. Cerebrovasc Dis 2001;11:119-127.

52 Mahagne MH, David O, Darcourt J, et al: Voxel-based mapping of cortical ischemic damage using Tc 99m L, L-ethyl cysteinate dimer SPECT in acute stroke. J Neuroimaging 2004; 14:23-32.

53 Karonen JO, Vanninen RL, Liu Y, Ostergaard L, et al: Combined diffusion and perfusion MRI with correlation to single-photon emission CT in acute ischemic stroke. Ischemic penumbra predicts infarct growth. Stroke 1999;30:1583-1590.

54 Marchal G, Bouvard G, Iglesias S, et al: Predictive value of 99mTc-HMPAO-SPECT for neurological outcome/recovery at the acute stage of stroke. Cerebrovasc Dis 2000;10:817.

55 Berrouschot J, Barthel H, Hesse S, et al: Differentiation between transient ischemic attack and ischemic stroke within the first six hours after onset of symptoms by using 99mTc-ECD-SPECT. J Cereb Blood Flow Metab 1998;18:921-929. 
-56 Hatazawa J, Shimosegawa E, Toyoshima H, et al: Cerebral blood volume in acute brain infarction - a combined study with dynamic susceptibility contrast MRI and 99mTcHMPAO-SPECT. Stroke 1999;30:800-806.

57 Ueda T, Sazaki S, Yuh WTC, et al: Outcome in acute stroke with successful intra-arterial thrombolysis and predictive value of initial single-photon emission-computed tomography. J Cereb Blood Flow Metab 1999;19:99108.

58 Ezura M, Takahashi A, Yoshimoto T: Evaluation of regional cerebral blood flow using single photon emission tomography for the selection of patients for local fibrinolytic therapy of acute cerebral embolism. Neurosurg Rev 1996;19:231-236.

-59 Ryu YH, Chung TS, Yoon PH, et al: Evaluation of reperfusion and recovery of brain function before and after intracarotid arterial urokinase therapy in acute cerebral infarction with brain SPECT. Clin Nuc Med 1999;24:566-571.

60 Hjort N, Butcher K, Davis SM, et al: Magnetic resonance imaging criteria for thrombolysis in acute cerebral infarct. Stroke 2005; 36:388-397

-61 Mintorovitch J, Moseley ME, Chileuitt L, et al: Comparison of diffusion- and $\mathrm{T}_{2}$-weighted MRI for the early detection of cerebral ischemia and reperfusion in rats. Magn Reson Med 1991;18:39-59.

-62 Hoehn-Berlage M, Norris DG, Kohno K, et al: Evolution of regional changes in apparent diffusion coefficient during focal ischemia of rat brain: the relationship of quantitative diffusion NMR imaging to reduction in cerebral blood flow and metabolic disturbances. J Cereb Blood Flow Metab 1995;15:10021011.

-63 Moseley ME, Cohen Y, Mintorovitch J, et al: Early detection of regional cerebral ischemia in cats: comparison of diffusion- and $\mathrm{T}_{2^{-}}$ weighted MRI and spectroscopy. Magn Reson Med 1990;14:330-346.

-64 Minematsu K, Li L, Sotak CH, et al: Reversible focal ischemic injury demonstrated by diffusion-weighted magnetic resonance imaging in rats. Stroke 1992;23:1304-1310

65 Lansberg MG, Thijs VN, O’Brien MW, et al: Evolution of apparent diffusion coefficient, diffusion-weighted, and $\mathrm{T}_{2}$-weighted signal intensity of acute stroke. Am J Neuroradiol 2001;22:637-644.

-66 Knight RA, Dereski MO, Helpern JA, et al: Magnetic resonance imaging assessment of evolving focal cerebral ischemia: comparison with histopathology in rats. Stroke 1994; 25:1252-1261.

-67 Hossmann KA, Hoehn-Berlage M: Diffusion and perfusion MR imaging of cerebral ischemia. Cerebrovasc Brain Metab Rev 1995;7: 187-217.

68 Lovblad KO, Laubach HJ, Baird AE, et al: Clinical experience with diffusion-weighted MR in patients with acute stroke. Am J Neuroradiol 1998;19:1061-1066.
69 Bykowski JL, Latour LL, Warach S: More accurate identification of reversible ischemic injury in human stroke by cerebrospinal fluid suppressed diffusion-weighted imaging. Stroke 2004;35:1100-1106.

70 Loh PS, Butcher KS, Parsons MW, MacGregor L, Desmond PM, Tress BM, Davis SM: Apparent diffusion coefficient thresholds do not predict the response to acute stroke thrombolysis. Stroke 2005;36:26262631.

71 Lansberg MG, Thijs VN, Bammer R, Olivot JM, Marks MP, Wechsler LR, Kemp S, Albers GW: The MRA-DWI mismatch identifies patients with stroke who are likely to benefit from reperfusion. Stroke 2008;39:24912496.

72 Warach S, Chien D, Li W, et al: Fast magnetic resonance diffusion-weighted imaging of acute human stroke. Neurology 1992;42: 1717-1723.

73 Baird AE, Warach S: Magnetic resonance imaging of acute stroke. J Cereb Blood Flow Metab 1998;18:583-609.

74 Wittsack HJ, Ritzl A, Fink GR, et al; MR imaging in acute stroke: diffusion-weighted and perfusion imaging parameters for predicting infarct size. Radiology 2002;222: 397-403.

75 Albers GW, Thijs VN, Wechsler L, et al; DEFUSE Investigators: Magnetic resonance imaging profiles predict clinical response to early reperfusion: the diffusion and perfusion imaging evaluation for understanding stroke evolution (DEFUSE) study. Ann Neurol 2006;60:508-517.

76 Davis SM, Donnan GA, Parsons MW, et al: Effects of alteplase beyond $3 \mathrm{~h}$ after stroke in the Echoplanar Imaging Thrombolytic Evaluation Trial (EPITHET): a placebo-controlled randomised trial. Lancet Neurol 2008;7:299-309.

77 Shih LC, Saver JL, Alger JR, et al: Perfusionweighted magnetic resonance imaging threshold identifying core, irreversibly infarcted tissue. Stroke 2003;34:1425-1430.

78 Schlaug G, Benfield A, Baird AE, et al: The ischemic penumbra: operationally defined by diffusion and perfusion MRI. Neurology 1999;53:1528-1537.

79 Dijkhiizen RM, Berkelbach van der Sprenkel JW, et al: Regional assessment of tissue oxygenation and the temporal evolution of hemodynamic parameters and water diffusion during acute focal ischemia in rat brain. Brain Res 1997;750:161-170.

80 Hossmann KA, Fischer M, Blockhorst K, Hoehn-Berlage M: NMR imaging of the apparent diffusion coefficient (ADC) for the evaluation of metabolic suppression and recovery after prolonged cerebral ischemia. J Cereb Blood Flow Metab 1994;14:723-731.

-81 Hasegawa Y, Fisher M, Latour LL, et al: MRI diffusion mapping of reversible and irreversible ischemic injury in focal brain ischemia. Neurology 1994;44:1484-1490.
82 Kidwell CS, Alger JR, Saver JL: Beyond mismatch: evolving paradigm in imaging the ischemic penumbra with multimodal magnetic resonance imaging. Stroke 2003;34: 2729-2735.

83 Butcher KS, Parsons M, MacGregor L, Barber PA, Chalk J, Bladin C, Levi C, Kimber T, Schultz D, Fink J, Tress B, Donnan G, Davis $S$ : Refining the perfusion-diffusion mismatch hypothesis. Stroke 2005;36:11531159.

84 Butcher KS, Parsons M, Allport L, Lee SB, Barber PA, Tress B, Donnan GA, Davis SM: Rapid assessment of perfusion-diffusion mismatch. Stroke 2008;39:75-81.

85 Takasawa M, Jones PS, Guadagno JV, et al: How reliable is perfusion MR in acute stroke? Validitation and determination of the penumbra threshold against quantitative PET. Stroke 2008;39:870-877.

86 Kidwell C, Starkman S, Jahan R, et al: Pretreatment MRI penumbral pattern predicts good clinical outcome following mechanical embolectomy (abstract). Stroke 2004;35:294.

87 Kidwell C, Alger JR, Saver JL: Evolving paradigms in neuroimaging of the ischemic penumbra. Stroke 2004;35:2662-2665.

88 Hacke W, Albers G, Al-Rawi Y, et al: The Desmoteplase in Acute Ischemic Stroke Trial (DIAS): a phase II MRI-based 9-hour window acute stroke thrombolysis trial with intravenous desmoteplase. Stroke 2005;36:6673.

89 Furlan AJ, Eyding D, Albers GW, et al: Dose Escalation of Desmoteplase for Acute Ischemic Stroke (DEDAS): evidence of safety and efficacy 3 to $9 \mathrm{~h}$ after stroke onset. Stroke 2006;37:1227-1231

90 Thomalla G, Schwark C, Sobesky J, et al: Outcome and symptomatic bleeding complications of intravenous thrombolysis within $6 \mathrm{~h}$ in MRI-selected stroke patients: comparison of a German multicenter study with the pooled data of ATLANTIS, ECASS and NINDS tPA trials. Stroke 2006;37:852-858.

-91 Kohrmann M, Juttler E, Fiebach JB, et al: MRI versus CT-based thrombolysis treatment within and beyond the $3 \mathrm{~h}$ time window after stroke onset: a cohort study. Lancet Neurol 2006;5:661-667.

92 Ribo M, Molina CA, Rovira A, et al: Safety and efficacy of intravenous t-PA stroke treatment in the 3- to 6-hour window using multimodal transcranial Doppler/MRI selection protocol. Stroke 2005;36:602-606

93 European Stroke Conference (Glasgow; United Kingdom 2007; Highlights. http:// eurostroke.com/esc_gla_highlights.htm (accessed Jan 17, 2008)

-94 Hacke W, Furlan AJ, Al-Rawi Y, et al: Intravenous desmoteplase in patients with acute ischaemic stroke selected by MRI perfusiondiffusion weighted imaging or perfusion CT (DIAS-2): a prospective, randomised, double-blind, placebo-controlled study. Lancet Neurol 2009;8:126-128. 
$>95$ Del Zoppo G, von Kummer R, Hamann G: Ischemic damage of brain microvessels: inherent risks for thrombolytic treatment in stroke. J Neurol Neurosurg Psychiatry 1998; 65:1-9.

-96 Hunter GJ, Hamberg LM, Ponzo JA, et al: Assessment of cerebral perfusion and arterial anatomy in hyperacute stroke with three-dimensional functional CT: early clinical results. Am J Neuroradiol 1998;19:29-37.

$>97$ Lev MH, Segal AZ, Farkas J, et al: Utility of perfusion-weighted CT imaging in acute middle cerebral artery stroke treated with intra-arterial thrombolysis: prediction of final infarct volume and clinical outcome. Stroke 2001;32:2021-2028.

98 Wintermark M, Sesay M, Barbier E, et al: Comparative overview of brain perfusion imaging techniques. Stroke 2005;36:20322033.
99 Schramm P, Schellinger PD, Klotz E, et al: Comparison of perfusion computed tomography and computed tomography angiography source images with perfusionweighted imaging and diffusion-weighted imaging in patients with acute stroke of less than $6 \mathrm{~h}$ duration. Stroke 2004;35:16521658.

100 Wintermark M, Reichart M, Cuisenaire O, et al: Comparison of admission perfusion computed tomography and qualitative diffusion- and perfusion-weighted magnetic resonance imaging in acute stroke patients. Stroke 2002;33:2025-2031.

101 Parsons MW, Pepper EM, Chan V, et al: Perfusion computed tomography prediction of final infarct extent and stroke outcome. Ann Neurol 2005;58:672-679.

102 Wintermark M, Meuli R, Browaeys P, et al: Comparison of CT perfusion and angiography and MRI in selecting stroke patients for acute treatment. Neurology 2007;68:694697.
103 Kang DW, Chalela JA, Dunn W, Warach S: MRI screening before standard tissue plasminogen activator therapy is feasible and safe. Stroke 2005;36:1939-1943.

104 Muir KW, Buchan A, von Kummer R, et al: Imaging of acute stroke. Lancet Neurol 2006;5:755-768.

105 Todo K, Moriwaki H, Saito K, et al: Early CT findings in unknown-onset and wakeup strokes. Cerebrovasc Dis 2006;21:367371.

106 Hellier KD, Hampton JL, Guadagno JV, et al: Perfusion CT helps making for thrombolysis when there is no clear time of onset. J Neurol Neurosurg Psychiatry 2006;77: 417-419.

107 Skagervik I, Wikholm G, Rosengren L, et al: Brain CT perfusion in stroke in progression. Eur Neurol 2008;59:98-100. 